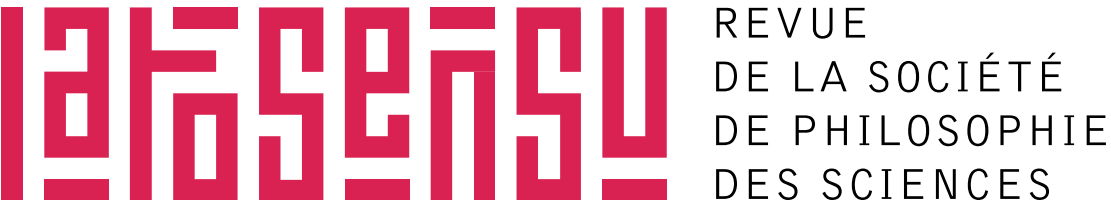

Vol $8 N^{\circ} 22 O 21$

DOI http://dx.doi.org/10.20416/LSRSPS.V8I2.3

\section{Marco Casali}

\section{EXPLORING THE BOUN-}

\section{DARIES AND ONTOLOGY}

of Psychiatric Disor-

DERS (PDS) USING THE

Homeostatic Pro-

PERTy Cluster (HPC)

MODEL

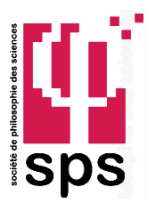




\section{Marco Casali}

\section{EXPLORING THE BOUNDARIES AND ONTOL- ogy of Psychiatric Disorders (PDs) using the Homeostatic Property Cluster (HPC) MODEL}

\author{
Sommaire \\ 1 - Introduction \\ 2 - Psychiatric practice: the continuous/discrete \\ problem and the operational synthesis \\ 3 - The operational synthesis is not an attempt \\ to further ontological exploration \\ 3.1 - The positioning of our proposal within \\ the existing literature in the philosophy of psychiatry \\ 4-Our first proposal: linking the classical \\ discrete/continuous debate with the HPC model \\ 4.1. The HPC model of natural kinds \\ 4.2 The extrapolation problem \\ 4.3 The geometrical metaphor: the continuous \\ and discrete synthesis within the HPC model \\ 5. Our second proposal: the ontology \\ of HPC compared to PDs \\ 6. Conclusions
}

\section{Introduction}

This paper aims to propose a perspective that can improve our ontological understanding of PDs. More specifically, the aim of the present work is to address the two following points. The first links two debates that are usually kept separate regarding some practical and philosophical aspects of PDs. The second explores a novel ontology for PDs.

This first point proposes linking two debates that are usually considered distinct: 1 ) the debate within practical psychiatry about the boundaries of PDs (e.g. are PDs discrete or continuous entities?; Bjelland et al. 2009; Broman-Fulks et al. 2010; Haslam 2003; Kasanin 1994; Keshavan et al. 2011; Muthén 2006; Ruscio, Haslam and Ruscio 2006; Shear et al. 2007; Widiger and Samuel 2005); 2) and the philosophical debate around how PDs are framed in the HPC model (Borsboom 2008; Borsboom and Cramer 2013; Fried 2015; Kendler 2012 and Kendler, Zachar and Craver 2011).

On the one hand, practical psychiatrists attempting to resolve
In this article we show that, even though the classification and diagnosis of Psychiatric Disorders (PDs) are performed according to essentialist terms, the psychiatric diagnoses currently employed, (i.e., clinical psychiatry) do not actually meet these criteria. Diagnosis is performed operationally. In this paper, we suggest a change of perspective. We reject essentialism relating to PDs and argue for the Homeostatic Property Cluster (HPC) model, which allows a greater insight into the ontology of PDs than the operational perspective. More specifically, we argue that the HPC model allows for a synthesis of continuous and discrete methods of understanding the boundaries between PDs. Finally, we specify in a more general manner, the kind of ontology we deal with when adopting the HPC model, arguing that this model can be viewed as a mirror device, reflecting the ontological features of PDs.

Keywords: Psychiatric Disorders (PDs), Homeostatic Pro-
perty Cluster (HPC), essentialism, operational synthesis,
ontology.

the question of PDs' boundaries synthesize discrete and continuous systems. Within a spectrum of symptoms, they use a cut-point/cut-off to demarcate boundaries between disorders, and between the state of health and disordered health. We show that this synthesis is operational, namely, psychiatrists define the boundaries of PDs according to the way in which they are measured. On the other hand, regardless of their position on how PDs are framed, scholars of the second debate at least agree that the HPC model is ontologically embedded. Indeed, this model was developed for the first time by Boyd (1988) while attempting to resolve ambiguities in the definition of species as natural kinds. In recent years, the HPC model has been proposed as a tool for classifying PDs. Our proposal underlines how the synthesis of discrete and continuous systems, used in clinical practice, is different from the synthesis (that we will propose) when working within the HPC model of natural kinds. Indeed, if in clinical practice this synthesis is operational, we propose that in the HPC model, the synthesis is ontologically embedded. We propose a visualization of the synthesis between discrete and continuous systems within the HPC model as substantiation. 
Therefore, in this article, we aim to shift from an operational synthesis to a new, theoretical one. By "theoretical" we mean a synthesis that is in some sense embedded in ontology. Considering a realist position, we believe that ontology could be useful in understanding, explaining and classifying PDs.

The second points explores this ontology. What does ontology mean for PDs in the context of the HPC framework? In the fields of philosophy of psychology, philosophy of psychiatry and philosophy of mind, PDs are often conceived as ontologically "strange objects". In the literature, there is some awareness that when dealing with PDs, naïve ideas of realism fail (Jablensky 2012, 2016; Kendell and Jablensky 2003; Kendler, Zachar and Craver 2011; Murphy 2015; Rodrigues and Banzato 2015; Schaffner 2012). Therefore, the majority of the debate in relation to PDs in terms of philosophy of psychiatry/psychology and mind could be summed up with the question: to what definition of reality do we have recourse when we talk about PDs? This is difficult to answer because essentialism, pragmatism (e.g., operational solutions) and anti-psychiatrist positions ${ }^{1}$ are just around the corner. In relation to our specific topic, the question could be rephrased as follows: what kind of ontology do we have when we frame PDs within the HPC model? To avoid falling into the aforementioned positions, we propose an exploration that attempts to define this kind of ontology.

Instead of continuing to follow etiological evidence, we wish to shift attention to the robustness of clusters of symptoms. In broad terms, by "robustness" we mean clusters of symptoms that repeat themselves several times among different patients. Our proposition is that the HPC model allows us to focus on this robustness. This alternative way of framing the ontology of PDs is detached from traditional - and unsuccessful - etiological evidence-seeking.

The paper is organized as follows. In the second section we describe the operational synthesis between the discrete and continuous perspectives of PDs in practical psychiatry. In the third section, we explore the reasons why that synthesis is not ontologically informative. In the fourth section, we argue for our first proposal, namely, the fact that linking the classical debate relating to PDs' boundaries (i.e., discrete/continuous systems of classification) with the HPC model could be a positive way of reframing that debate. In the final section, we argue for our second proposal, namely, in which sense can we infer more in relation to the ontology of PDs, using the HPC model.

\section{Psychiatric practice: the continuous/discrete prob- lem and the operational synthesis}

In mainstream psychiatric thought, PDs are most frequently considered from an essentialist perspective (Adriaens and De Block 2013; Deacon 2013; Haslam 2000; Wade and Halligan 2004; Whitaker 2001, 2010). In general, an essentialist thinker conceives PDs as having necessary and sufficient properties. Most of the time, these properties are identified in the brain as brain damage (e.g., brain lesions) or brain modification (e.g., the famous example of the spirochete bacterium, see Deacon (2013); Fried (2015); Kendler et al. (2011)). ${ }^{2}$ One of the most historically important essentialist thinkers, Emil Kraepelin (1856-1926), (for an overview see Jablensky (2012)), searched for lesions in his patients' brains, in order to enucleate "disease entities" (Aragona 2015, p. 35). ${ }^{3}$

However, in clinical practice, psychiatrists do not actually embrace this perspective as it is affected by a number of criticalities ${ }^{4}$. Among them, and one of the most controversial questions at the heart of practical psychiatry, is whether PDs are continuous or discrete entities. In this context, clinicians are not essentialists. On the contrary, their solution is to synthetize discrete and continuous ideas about PDs in a practical fashion, to make room for practical concerns (e.g., clinical classification) $)^{5}$. To be exact: in a scenario in which there is a scale of continuous of symptoms/signs, clinicians operationally introduce cut-points/cut-offs that enable PDs to be understood as discrete entities ${ }^{6}$. This discreetness is a necessary feature of clinical practice. This solution, that we will call op-

\footnotetext{
1. The more important anti-psychiatric position was developed during the 196os (for an overview, see Cooper (20o7, chapter 2); see also Rodrigues and Banzato (2015, p. 52)). These scholars tried to discourage the study of PDs because - they say - there is no such thing as "mental illness" (Szasz 196o, p. 113). Following the work cited by Cooper (2007), a paradigmatic study of the anti-psychiatrist concept was conducted by Rosenhan (1973), in relation to "pseudo-patients" (i.e., sane people who present themselves to a psychiatrist as insane) and underlined how psychiatrists were unable to distinguish between sane and insane patients (regarding this point, see also Decker (2007, p. 344)). Nonetheless, we must note recent studies which suggest that the work of Rosenhan may have been fraudulent. For example, Cahalan (2019) argues that the 1973 study may have misrepresented or fabricated evidence (we are grateful to an anonymous reviewer for suggesting this last point).

2. For a deeper analysis concerning explanatory reductionism in the study of PDs, see Borsboom, Cramer and Kalis (2019).

3. We should nevertheless point out that Kraepelin, in later life, questioned the accuracy of his former, essentialist assumptions. In relation to this point see, Kraepelin (1913, p. 345) quoted in Decker (2007, p. 356); we are grateful to an anonymous reviewer for suggesting this point.

4. One of the major criticalities of this approach is that, to date, no empirical evidence supports the idea of PDs as brain damage or brain modifications. For more philosophical critics to this approach see, Bolton (2012); Deacon (2013); Fried (2015); Kendler, Zachar and Craver (2011); Zachar et al. (2015).

5. For an analysis of the difference between validity and utility, see Kendell and Jablensky (2003) and Jablensky (2016).

6. In light of the theoretical character of the present work, we do not focus on the quantitative statistical analysis of psychiatric disorders. For such an analysis, see Muthén (2006); for an analysis of taximetrics approaches, see Ruscio, Haslam and Ruscio (2006); for a more technical discussion, see Walters, McGrath and Knight (2010); for the application of a taxometric approach (MAXEIG, MAMBAC and LMODE) to a specific example (anxiety sensitivity), see Broman-Fulks et al. (2010). See also Haslam (2003).
} 
erational synthesis, is a solution dictated by practical necessity (i.e., the necessity of clear and discrete classification for diagnosis and treatment) and not by some sort of ontological exploration. In the following we will illustrate three examples that highlight this tendency toward such operational synthesis in practical psychiatry. Our goal is to underline how this kind of synthesis is not an informative one, as regards the nature of PDs; it does not add anything to our ontological understanding of PDs. On the other hand, we think improving ontology is essential in the study of PDs insofar as the improvement provides us with a new way of seeing, explaining and classifying PDs.

A famous example concerns the indistinct (or "fuzzy") boundary between schizophrenia and bipolar disorder, which Kraepelin was the first to highlight. In 1933, Kasanin ${ }^{7}$ attempted to resolve this by introducing the intermediate "schizoaffective disorder". Widiger and Samuel (2005) describe it as the "grey area between schizophrenia and mood disorders" (p. 496). According to DMS-III, schizoaffective disorder was introduced "for those instances in which the clinician is unable to make a differential diagnosis with any degree of certainty between Affective Disorder and either Schizophreniform Disorder or Schizophrenia" (APA 1980, p. 202). However it is "perhaps paradoxical to create a distinct clinical entity that demarcates the overlapping and nebulous area between two other disorders" (Widiger and Samuel 2005, p. 496); see also Jablensky (2012, p. 82) and Keshavan et al. (2011). While the introduction of schizoaffective disorder could have simplified classification, it did not resolve the problem because it was never unanimously accepted. Other proposals were subsequently developed but they only confused the matter (see Jablensky (2012, p.82)). We conceive the category of schizoaffective disorder as operational because it was only created to fit the aims of clear and discrete classification. In addition, this operational modification is unsatisfactory insofar as it was not unanimously accepted. Consequently, it does not lead to a homogenized diagnosis.

Our second example is drawn from Keshavan et al. (2011). A statistical study of 762 patients with signs and symptoms of both schizophrenia and bipolar disorder was conducted, to analyze the overlap between disorders.

Using the "Schizo-Bipolar Scale" - a dimensional scale based on four categories - Keshavan et al. identified the following: (a) bipolar (243 patients); (b) schizoaffective bipolar (119 patients); (c) schizoaffective depressed (59 patients) and (d) schizophrenia (341 patients). This showed that in the case of these disorders there is "a hybrid conceptualization model with a representation of cases with prototypic schizophrenia or bipolar disorder at the extremes, but a large group of patients on the continuum between them that traditionally would be considered schizoaffective" (p. 1).

We have to specify that bipolar, schizoaffective dipolar, schizoaffective depressed and schizophrenia, are categories by the DSM-IV-TR. ${ }^{8}$ To assign the patients to one of these four categories, the authors used the Structured Clinical Interview (SCID) for DSM-IV-TR (Keshavan et al. 2011, p. 3). The SCID is a first person, semi-structured interview that permits clinicians to diagnose PDs within the DSM schema (this is the case in the DSM-IV-TR). The SCID is mainly based on reliability (Glasofer, Brown and Riegel 2015, p. 2-3). The interview does not consider the ontology of patients' PDs, but rather was developed to assist clinicians in accurately classifying patients in light of the available DSM classifications. After undergoing SCID, the diagnosis of patients is defined in terms of DSM categories. The authors will then make an assessment of the disease in terms of DSM categories on the scale - the Schizo-Bipolar Scale - in order to evaluate the range of continuity between these different categories. In this example, the operational element of the diagnosis resides in the SCID interview process. This permits the assignation of discrete and fixed categories in DSM-IV-TR classification in relation to patients, who present a continuum of symptoms, without recourse to ontology. ${ }^{9}$

The third example comes from Bjelland et al. (2009). They attempt to formulate an operational synthesis by deploying empirical evidence. They argue that discrete and continuous approaches might be considered complementary, not dichotomous, and use a dimensional scale (continuous) called the Hospital Anxiety and Depression Scale (HADS) in which the boundaries between depression and anxiety disorder overlap. The HADS is divided in two sub-scales: HADS-A which is specific to anxiety disorder and HADS-D which is specific to depression.

The HADS consists of questionnaires for patients with uncertain diagnoses. Bjelland et al. (2009) used a large population sample: 60,869 patients with uncertain diagnoses. HADS-A contained questions concerning restlessness, worry and panic attacks; HADS-D contained questions concerning anhedonia (inability to feel pleasure during usually satisfying activities), psychomotor retardation, and depressive states. editions of DSMs, see Aragona (2015); Cooper (2005); Frances et al. (1993); Grob (1991); Kendler and First (2010); Tsou (2011).

9. We need no further details concerning the SCID interview because it serves only as a guide to diagnose disorders in the DSM systems of classification. In light of the fact that DSMs are not systems of classification based on ontological assumptions (see for example, Zachar et al. (2015)), we infer that the SCID interview does not move toward ontology either. 
Patients could answer on a scale from o (symptom not present) to 3 (symptom present). If the score of one or both of the two sub-sections (HADS-A, HADS-D) was greater than or equal to 8 , then the patient was diagnosed as suffering from depression (HADS-D $\geq 8$ ), anxiety disorder (HADS-A $\geq 8$ ), or both (HADS-D and HADS-A $\geq 8$ ). A score of 8 identified a cut-off (or cut-point), marking a discrete point along this continuous scale. Possible results were: (a) depression, (b) anxiety disorder, (c) comorbidity, (d) no disorder. The authors concluded that a complementary approach - consisting of the HADS in combination with precise cut-offs - is necessary for an accurate diagnosis. ${ }^{10}$

These three examples clearly show how the synthesis between discrete and continuous definitions is operational. This reflects clinical necessity (i.e., the need for clear and discrete classifications) and the way in which clinicians measure PDs (i.e., a spectrum of symptoms is measured and the PD defined as occupying a specific range).

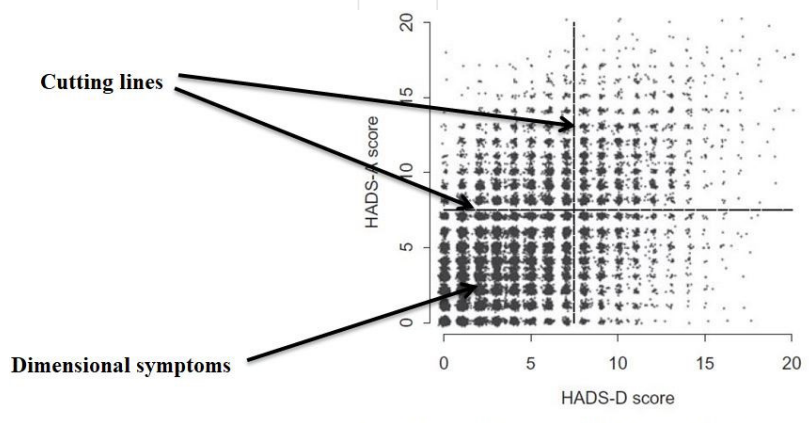

Figure 1 The distribution of HADS-A and HADS-D scores (fuzzy scatterplot). Categories: lower left, non-cases; lower right, 'pure' depression'; upper left, 'pure' anxiety; upper right, 'co-morbid' anxiety disorder and depression. The HUNT 2 study. $N=60869$

Figure 1. The distributions of HADS-A and HADS-D scores. The dimensional symptoms (spectrum of symptoms) are represented as a carpet of points. "The cutting lines" delimit specific areas that correspond to specific PDs (modified image by Bjelland et al. (2009)).

Figure 1 (which originates from the third example of the work of Bjelland et al. (2009) visualizes the operational synthesis. Continuity is exemplified by the spectra of symptoms and discreetness by the cut line delimiting specific disorders ${ }^{11}$. The cut lines are the conventional element of the classification. Let us underline that conventional classifications are not necessarily arbitrary: they reflect practical aims and constraints (e.g., social, practical and medical). Nevertheless, they are not ontologically informative. In the next section we justify this last assertion.

\section{The operational synthesis is not an attempt to further ontological exploration}

Besides the problems relating to this approach (e.g., the grey area between disorders in the first example and the absence of ontological conclusiveness in the second) our criticisms focus mainly on arguments that the operational synthesis does not enable understanding of the ontology of PDs. We justify this assertion by linking the operational synthesis (established in the examples in section 2) with the philosophical position of "practical kind", first developed by Zachar (2000). Let us consider Haslam's (2002a) definition of "practical kind", which is particularly clear and is in line with Zachar's idea: ${ }^{12}$

"In the case of what I call practical kinds, there is no underlying discontinuity, so although imposing a diagnostic boundary is arbitrary in principle, there are practical constraints on the boundary's placement" (Haslam 2002a, p. 206).

In relation to practical kinds, boundaries are recognized out of clinical necessity - even in the absence of underlining discontinuity. Haslam attempts to suggest - as we have correctly understood - ways of recognizing the differences between the internal (e.g., ontological) and external (e.g., the social, practical, medical) dimensions. From a practical perspective, the "diagnostic boundary" is arbitrary in the sense that it does not reflect underlying discontinuity, yet since it reflects social/practical/medical constraints, at the same time, it is not arbitrary. Therefore, for Haslam the boundaries of practical kinds are ontologically arbitrary (because we do not know the inner structure of a PD) but not "externally arbitrary" (because they are based on social/practical/medical rationales).

As already discussed, the operational synthesis is the clinical practice of adding a cut-point within a spectrum of symptoms. As already mentioned, the word "operational" refers to the fact that psychiatrists define PDs' boundaries by the way in which they measure them (i.e., they measure a spectrum of symptoms and then define PDs as occupying a specific range). This methodological approach present within clinical practice could be linked to the philosophical account of "practical kinds" by Zachar (2000). In the spirit of an instrumentalist approach to science (Dewey 1925; James 1907), Zachar's ac-

10. A similar conclusion is also reached by Shear et al. (2007): "we believe that the most useful approach would be to add cross-cutting anxiety assessments to the existing categorical system" (p. S59).

11. However, more recent research has been moving toward a "staging model" which claims that different points along the continuum might be used to select precise treatment strategies.

12. We should note that their position concerning practical kinds is not exactly the same. While for Zachar, the concept of practical kinds is the main concept that "subvert[s] the opposition of natural and artificial kinds" (Haslam 2002b, p. 204), for Haslam practical kinds are "just one of several kinds of kinds" (ibid.); see also Haslam (2002a). However, this difference does not affect our general argument because the broad definition that follows is actually shared by both authors. 
count states that the purpose of classification is the achievement of scientific goals, including reliable diagnoses (Kendler, Zachar and Craver 2011, p. 1146). More specifically, the account focuses on reliability ${ }^{13}$ by leaving out validation ${ }^{14}$ (see also Rodrigues and Banzato (2015, p. 55)). Kendler, Zachar and Craver (2011) underline that for pragmatists, if "we can describe how [patients] will behave, detail how they came to be that way, integrate the disorder category with well-tested theories in genetics, physiology and cognitive science, and also cure the disorder, then, the pragmatist insists, nothing important is added by claiming: 'in addition to all that, the disorder is real"' (Kendler, Zachar and Craver 2011, p. 1146), referring to Fine (1984). ${ }^{15}$

In this last quotation is an important commitment to pragmatism that could be useful to our discussion. In pragmatists' work, ontology does not matter: their lines of enquiry are guided by practical outcomes; whether their enquiries are ontologically descriptive or not, is a secondary and contingent consequence. Indeed, in Haslam's definition of practical kinds, the only constraints described are external and practical. Ontology is not referred to ${ }^{16}$ Nevertheless, care must be taken when making claims relating to pragmatists' relationships with ontology. Even if their direction is driven by a "pragmatic engine", this does not mean that their achievement precludes ontological implications. For pragmatists, any ontological achievements are contingent. By contrast, for realists, ontology guides the research.

We believe that what we described as an operational synthesis (section 2) is connected with the work of pragmatists such as Zachar. This link serves our thesis. Indeed, the cut-point in a continuum of symptoms/signs - which we called operational synthesis - is not dictated by the effort to discover features of the real world, but to achieve clinical goals in the light of examined cases. ${ }^{17}$ In respect of this, ontological improvement would only ever be a secondary and contingent consequence.
If we accept the pragmatic approach that regards ontology as contingent, as well as the idea that our operational synthesis could be seen as a pragmatic methodology, then we can also reasonably affirm that the synthesis is ontologically contingent too. Thus, we argue that while the operational synthesis is pragmatically applicable, it is not ontologically informative.

To sum up, we have highlighted that in clinical practice, psychiatrists are not committed to an essentialist perspective. On the contrary, to achieve scientific goals they use pragmatic expediency. We have identified what we call an operational synthesis in classifying PDs. Furthermore, by linking this particular synthesis with the pragmatic approach proposed by Zachar, we argued that this synthesis does not improve the ontological understanding of PDs.

The purpose of this article is to propose a line of enquiry within which ontology is the main guide. More specifically, we aim to answer the classic question of whether PDs' boundaries are continuous or discrete entities, using the HPC model, which was initially developed within the philosophy of biology. Before entering into details, it is necessary to understand where our proposal is best located within the existing literature relating to the philosophy of psychiatry.

\subsection{The positioning of our proposal within the existing literature in the philosophy of psychiatry}

The application of the HPC model to PDs is not new; numerous authors have already discussed it (Borsboom 2008;

13. The term "reliability" refers to the capacity of clinicians to use technical words for the same things/phenomena in different clinical contexts (Aragona 2015, p. 36). Roughly, an acceptable level of reliability reflects the fact that different clinicians in different contexts would agree on diagnostic criteria and consequentially, with similar patients, they would provide similar diagnoses.

14. $n$ this context, "validity" is intended in its general sense: "validity is supposed to be about what is really there" (Murphy 2015, p. 6o). In section 5, we give a more sophisticated definition of validity, derived from Aragona (2015). For a general perspective on the most recent studies into validation, see the collective book by Zachar et al. (2015).

15. Clarification is needed here. In the quote by Kendler, Zachar and Craver (2011, p.1146) that refers to Fine (1984) it seems that treatments, positive cures and other scientific goals are around the corner. However, this is not at all obvious. For this reason, we separate two steps: the grouping of classifications and the selection of treatments. These are two different things, spatially and temporally separate. In the present context, when we write that a diagnosis "works", we refer only to the pragmatic idea of creating adequate classifications in light of examined cases to help select the relevant treatment. We omit the question as to whether these treatments "work" because this does not permit us to make theoretical statements - treatment efficacy is particularly dependent upon empirical variables. 16. An objection could be raised here. Within the definition of practical kinds, ontology is mentioned: "[...] there is no underlying discontinuity". Even if "there is" appeals to ontology, the following "no" reflects a negation of it. Therefore, no positive meaning is attributed to ontology, concerning the definition of the practical kinds under proposal.

17. On the contrary, one could object that the work of pragmatists is ontologically embedded for reasons other than contingent reasons. Since clinical goals are based on examined cases, the conviction that the classifications they are making reflect certain features of the external world (i.e., features of human beings) could be reinforced. We answer this by saying that this is a general objection to pragmatic approaches - not specifically to our arguments. We concur by stating that the examined cases could tell us something about the ontology of PDs (we will specify in which sense in sections 4 and 5); the problem is that the ontology of PDs does not figure among the main goals of pragmatists (see the previous part of this section). In addition, our proposal could be seen as additional and not substitutive to the operational/pragmatist perspective. We try to figure out the ontology that pragmatics "leave out" (but which they usually do not refute) during investigations into PDs. 
Borsboom 2017; Borsboom and Cramer 2013, Fried 2015, Hauswald and Keuck 2017; Kendler 2012; Kendler, Zachar and Craver 2011; Tabb 2019; Tsou 2016).

In general, as summarized by Hauswald and Keuck (2017, p. 101), two different attitudes in the study of PDs can be identified. On the one hand, there are the "optimistic" authors who maintain that the process of classifying PDs is a "journey towards even greater epistemic accuracy and scientific adequacy" (Hauswald and Keuck 2017, p. 101; Murphy 2006, 2015; Tsou 2016). On the other hand, "pessimistic" authors (Bolton 2008, 2012) affirm that there is no possible means of objectively classifying PDs.

Scholars who discuss PDs and the HPC model, could be located in the "optimistic" framework because the majority write constructively on this topic (i.e., they have a generally positive attitude in applying the HPC model to PDs). Nevertheless, there remains an important difference, for while certain authors imply the idea of underlying mechanisms ${ }^{18}$ in their accounts (Kendler, Zachar and Craver 2011), others do not (Borsboom 2008, 2017; Borsboom and Cramer 2013, Fried 2015).

This difference is fundamental as it gives rise to different metaphysical positions. While the former presupposes that the real structure of PDs has to be examined by means of certain mechanisms (e.g., neurological, biological, physiological, etc.) underlying property clusters, the latter proposes that this structure has to be researched at different levels (e.g., the property cluster level). We concur with this second line of research.

If it is true that the way in which we approach PDs through the HPC model - believing that they can say something positive about their ontology - could be seen as "optimistic", we are, nevertheless, "pessimistic" in relation to the main direction (i.e., etiological research or the search for underlying mechanisms) of the research. We are skeptical about the possibility that etiological/biological causes for PDs will be discovered (regarding this point, see also Borsboom, Cramer and Kalis (2019)). More explicitly, the chief difference in our work, compared to that of other research, is our proposition of a clear-cut metaphysical position. Indeed, we propose an HPC model for PDs that presents a new conception of ontology (sketched in section 5) which does not need to incorporate any underlying mechanisms.

The HPC model was initially developed as an alternative to the essentialism of biological species as natural kinds. More specifically, a species was described as a cluster of properties with underlying mechanisms ${ }^{19}$ that "homeostatically" maintain these properties. This type of description helps to avoid the use of necessary and sufficient properties, which, for the concept of species, was difficult to understand. By means of this new ontological view in relation to kinds (clusters of properties, underlying mechanisms), this model did provide new ways of elaborating on inductions and explanations. ${ }^{20}$ We propose that we can visualize a synthesis between discrete and continuous boundaries within this model. If the model is committed to a certain type of ontology, consequentially, the proposed synthesis will be affected by this ontology too. The questions concerning the type of ontology we are dealing with, when we discuss the HPC model in relation to PDs, will be the second original idea of the paper. In light of the density of the argument, we propose the following organization:

1. we provide a brief overview of the HPC model and its origins (section 4.1);

2. we outline the problem that occurs when extrapolating this model from the domain of the philosophy of biology, to the domain of the philosophy of psychiatry (section 4.2);

3. we illustrate in which sense the HPC model implies a synthesis between the discrete and continuous systems of classification (section 4.3);

4. we argue why this proposal matters for the purposes of understanding and classifying PDs (section 4.3);

5. once the HPC model has been embraced, we specify which kind of ontology it provides for PDs (section 5).

18. We have to note that the status of the underlying mechanism is interpreted differently. For example, Tsou (2016, p. 410) writes that the idea of underlying mechanisms is implied in Boyd's account. On the contrary, Tabb (2019, p. 2185) states that Boyd's proposal is a "metaphysically permissive account" that does not require any "metaphysically-demanding underlying mechanisms" (ibid.). Furthermore, Tabb (2019) specifies that in Kendler, Zachar and Craver (2011), there exists a synthesis between Boyd's model and the recent idea of mechanisms, developed by Craver (2007, 2009). However, ultimately, what did Boyd originally write? In a 1999 paper he wrote: "[t]heir [a family $(F)$ of properties] co-occurrence is the result of what may be described as homeostasis: either the presence of some properties tends to favor the presence of others, or there are underlying mechanisms that tend to maintain the properties in F, or both" (pp. 143-144), quoted by Tsou (2016, p. 410) with emphasis added). The "or" in this quote is evidence that the author left open the possibility (at least in the quoted paper) of being more or less metaphysically demanding of mechanisms.

19. In the main text we explicitly state that the underlying mechanisms are characteristic of the HPC model, as this is the dominant interpretation in the literature of the philosophy of biology.

20. More specifically, the epistemological element of the HPC could be traced back to the accommodation thesis by Boyd (1999), postulating that "the theory of natural kinds is about how schemes of classification contribute to the formulation and identification of projectable hypothesis" (p. 147). If we assert that the ontological element of the HPC model relates to knowing kinds that say something about the world, the epistemological element relates to the inductions and explanations (e.g., projectable hypothesis) that this knowledge allows us to carry out. In addition, "kinds useful for induction or explanation always require that we accommodate our categories to the causal structure of the world" (1991, p. 139), namely, ontology always comes first. Only with ontologically-embedded kinds can we have proper inductions or explanations. 


\section{Our first proposal: linking the classical discrete/continuous debate with the HPC model}

\subsection{The HPC model of natural kinds}

The HPC model was developed within the discipline of the philosophy of biology (Boyd 1988, 1991; Ereshefsky 2007; Ereshefsky and Reydon 2015; Wilson, Barker and Brigandt 2007). It was proposed specifically in order to resolve the problem of biological species being conceived as natural kind, which can be summarized by the impossibility of characterizing species using the necessary and sufficient proprieties. The HPC model - proposed for the first time by Boyd (1988) - accords a central role to the clusters of properties, rather than relating to a single property. Indeed, in this model, a single property is neither necessary nor sufficient to identify a member of a kind/a species (see also Boyd (1991, p. 141)). Rather it is the clusters that identify a member of a kind/a species. For example, if species, $\mathrm{K}$, has the cluster of properties $\{\mathrm{A} ; \mathrm{B}$; C; D; E $\}$ and organism, Z, presents only, e.g., $\{B ; C ; E\}$ and another organism, Y, presents only, e.g., $\{\mathrm{A} ; \mathrm{B} ; \mathrm{D}\}$, according to the HPC model, both $\mathrm{Z}$ and $\mathrm{Y}$ share an element of the same clusters, therefore, they could be part of the same species/ kind..$^{21}$ The conditions of necessity and sufficiency are shifted from a single property to a cluster of properties. Through this shift, "necessity becomes more general" and "sufficiently becomes more varied" (Wilson, Barker and Brigandt 2007, p. 197). Since the cluster is more flexible concerning the identification of a member of a species, as a consequence, the HPC model is often conceived as an anti-essentialist model (see Wilson, Barker and Brigandt (2007)). The HPC model has since been applied to other biological objects (e.g., genes), (see Wilson, Barker and Brigandt (2007).

\subsection{The extrapolation problem}

To this point we have observed that the HPC model of natural kinds was originally used by Boyd to categorize biological species. However, more recently, it has also been used to cat- egorize PDs in order to avoid mainstream essentialist thinking in psychiatry. Borsboom (2008), Borsboom and Cramer (2013), Fried (2015), Kendler (2012) and Kendler, Zachar and Craver (2011) have already taken steps in this direction (see section 3.1). Nevertheless, before entering into detail, we wish to stress a more fundamental problem that arises when we extrapolate a model from one domain of studies and apply it to another. This problem - that we will call the extrapolation problem - has never been properly addressed with regard to the application of the HPC model to PDs. Yet it is a key point of discussion, as the correct conceptualization of PDs in the HPC model depends on this preliminary extrapolation. As a result, we will explore this in greater depth.

As previously mentioned, the key aim of the HPC model is to use clusters to propose an alternative to essentialist perspectives. However, no consensus exists in the literature in terms of applying this to PDs. There is a grey area in the literature, concerning the way in which the HPC model may be applied to PDs.

Firstly, the HPC model was developed in relation to the problem of biological species as natural kinds. However, debate rages as to whether PDs should be conceived as natural kinds or not. To date, it appears that the debate is a dead-end (for references and details, see section 5). Therefore, applying the HPC model to PDs as if they were natural kinds is problematic.

Secondly, it is not clear what the properties of the cluster refer to, though various proposals have been presented. For example, Boorsboom (2008) elaborates a variant of HPC that he calls "causal system perspective" in which the network of symptom-symptom causations specifies and represents a specific PD. Other conceptions of the properties of PDs could be schematized as follows: (a) they belong to different explanation levels (biological, psychological and cultural; see Kendler (2012) and the example relating to alcohol dependence), (b) they may be different types of entity (causal relations, mechanisms, dysfunctions, signs, symptoms), (c) they show heterogeneity in causal reciprocity (Boorsboom 2008).

Thirdly, the question concerning the underlying mechanisms is not clear. Since the role of these mechanisms in Boyd's account is quite ambiguous, its extrapolation in terms of PDs will also be ambiguous (see note 18).

In light of these heterogeneities, it might prove difficult to avoid errors (e.g., incorrect models) arising when a model that belongs to a specific field is extrapolated and applied to a different field, without accurate preliminary analysis. 
Nevertheless, a recent update - the "network of symptoms" to the HPC model proposes what we will call a "deflation" of the properties of the network (Borsboom and Cramer 2013). This simplifies the model by minimizing the concepts that have to be extrapolated. The basic idea is that a network of nodes, connected through a set of symptom-symptom causal relationships (p. 96; p. 101) makes up the core of the model. For example, in the framework of the network of symptoms, insomnia and fatigue (two symptoms of major depression) are depicted in causal relationships (insomnia $\rightarrow$ fatigue), see Borsboom, Cramer and Kalis (2019, p. 4). Attention is focused on symptom-symptom relationships, rather than on underlying or interdependent mechanisms, processes, dysfunctions or signs. Since the concepts (nodes, connections) are simple and are based on the general idea of a "network", the use of this model does not require extensive prior knowledge; problems deriving from extrapolation are minimized. Indeed, this theoretical shift from heterogeneous to specific property (i.e., symptoms) is corroborated by empirical evidence which underlines the robustness of these networks in terms of relationships, and elaborates upon a classification referring solely to these relationships, for example see Boorsboom and Cramer (2013). In the next section, in which we illustrate the geometrical metaphor, we propose the HPC model according to the terms of Borsboom and Cramer (2013) ${ }^{22}$ because it is not embedded in metaphysics, as is the classical HPC model of natural kinds. More specifically, the HPC model, conceived as a network of symptoms, is not metaphysically committed to the idea of PDs as natural kinds, since it is a model based solely on nodes and lines. We will return to this in section 5 . Currently, it suffices to note that the need to distance PDs from metaphysics is shared by many contemporary scholars (Cooper 2012). assume that clusters of properties can be visualized as geometric sets.

Nevertheless, in light of the discussion in the present section, we are now aware of the fact that when we conduct an extrapolation, it is not free from theoretical consequences. For this reason, we will use the already described "deflated" HPC model by Boorsboom and Cramer (2013), namely, the network of symptoms to illustrate our idea of synthesis in this geometric visualization.

As a simple geometric metaphor, the HPC model (as a network of symptoms) points to the constitutional idea of synthesis between continuity and discreetness. If the HPC model is visualized as a Venn diagram (figure 2), each set can be associated with a disorder. The letters are the symptoms; the arrows are the symptom-symptom relationships and the intersection between sets is the geometric illustration of comorbidity - which becomes an inherent feature of the landscape, rather than a flaw in the classification system. ${ }^{24}$

Indeed, if we consider the HPC model as a geometric metaphor, we can view how the characteristics of both continuous and discrete approaches are at play. Sets conceived as a circular (closed) line visually evidence the discreteness of the cluster and consequently, the discreetness of PDs. The intersection of sets clearly marks out comorbidity and provides the continuous element of the perspective.

\subsection{The geometrical meta- phor: the continuous and discrete synthesis within the HPC model}

In this section we will illustrate how the HPC model implies a synthesis between discrete and continuous systems of classification, using Venn diagrams. ${ }^{23}$ Specifically, we will

\footnotetext{
22. We will specifically use the account of Borsboom and Cramer (2013) in relation to the HPC model in the next section. Nevertheless, even if in the last section of the work we continue to refer to this account, we left open the possibility of integrating the HPC model with other non-metaphysically embedded accounts of this. 23. Venn diagrams illustrate all possible relationships between elements inside different sets. The elements of the sets are usually represented as points (or in our case as letters, see figure 2) on a plane and sets within a closed curved line. When two sets overlap, and there are elements in the overlapping space, this means that elements are shared by two different sets. In our specific context, elements represent symptoms and when two sets overlap and there are symptoms in the overlapping space, this means that those symptoms are shared by both sets. Sets can represent disorders, disorder concepts or a sub-cluster of symptoms (see figure 2).

24. For a different interpretation of comorbidity, see van Loo et al. (2012). In this study, the authors specifically argue for considering comorbidity in a positive sense, "as a validator for reclassifying PDs" ( $p .748)$.
} 


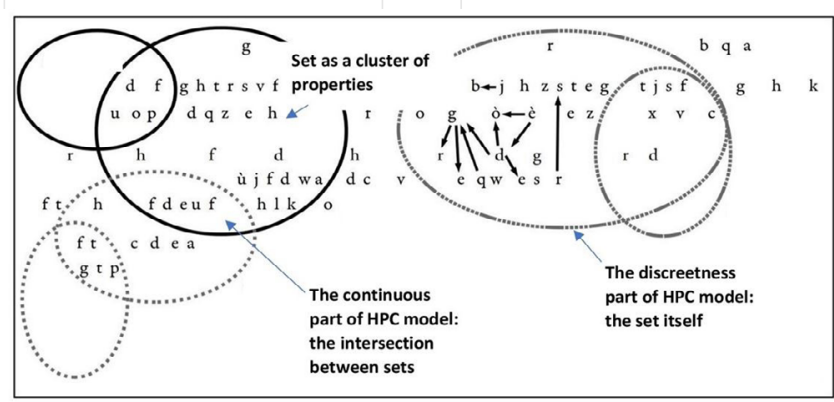

Figure 2. The HPC model as a Venn diagram. Letters are symptoms, arrows are symptom-symptom relationships (qualitatively pointing toward the right cluster only). Sets' boundaries bearing the same mark, represent the same disorder concept; smaller sets with the same mark represent the sub-cluster of that disorder (i.e., possible symptoms of patients). Sets with different marks represent different disorders. The continuous element of the HPC model is viewable as the intersection between sets; the discreteness of the HPC model is viewable as the sets themselves.

This geometric metaphor shows how a synthesis between discrete and continuous systems is implied in the HPC model. However, why is this geometrical metaphor significant for the discrete/continuous debate? More specifically, why does visualizing the discreteness and continuity in the HCP model help us? To answer this we (1) underline why the HPC model is conceived by researchers as an effective model for the classification of PDs; (2) sketch out the implications as to how PD boundaries are viewed in light of this "new" synthesis.

1. According to Kendler, Zachar and Craver: "what is needed is a scientific model of classification that accommodates variability in members of the kind, multiple etiologies, and probabilistic interactions between causes and outcomes" (Kendler, Zachar and Craver 2011, p. 1147). The HPC model, conceived, e.g., as a network of symptoms, appears to be an effective means of classifying PDs from an epistemological perspective (as an anti-essentialist model, it is a cluster of properties which focuses attention on symptom-symptom relationships, etc.) and an empirical one (it is in line with statistical data; see Boorsboom and Cramer (2013)). In this regard Kendler, Zachar and Craver assert that "although it is perhaps too early to make psychiatric classification fit [H]PC kinds, such an approach offers the most promising answer to the question of what kinds of things psychiatric disorders are" (Kendler, Zachar and Craver 2011, p. 1149). ${ }^{25}$ This is the context in which our proposal fits. Indeed, from an optimistic perspective we can reasonably assert that through this theoretical synthesis, a dead-end debate (or, at least, a very controversial one) concerning the boundaries of PDs, becomes linked to a well-quot- ed and fresh model in the studies of PDs - the HPC model. In addition, we recognize it as a wholly new non-operational way of thinking about PDs and their boundaries, namely a model that is ontologically informative (i.e., for the kind of ontology the HPC yields, see section 5).

2. The operational synthesis leads to arbitrary ${ }^{26}$ boundaries between PDs. However, although the line of enquiry is to discover the reality of the world, the operational synthesis can only accomplish scientific aims. If something "real" is discovered, it is only a secondary and a contingent consequence (see section 3). By contrast, the theoretical synthesis by the HPC model leads to explicative boundaries which tell us something about PDs and permits us to formulate epistemological and ontological questions. Furthermore, instead of asking whether "we have to carve the nature at its joint" (a typical question from an essentialist perspective, see Khalidi (1993)) or whether there is "a continuum between disorders or fixed boundaries between them" (cf. the continuous/discrete debate, section 2) it is more appropriate to ask "what are the ontological implications if we assert that the joints are themselves fuzzy?" (see also Boorsboom and Cramer (2013)) and "how can we improve the HPC model in light of the nature of these boundaries?” It is important to stress that "fuzziness" in the continuum/discrete debate is conceived only within the context of continuity, and is solved by elaborating an operational solution. From an essentialist perspective, the "fuzziness" of PDs' boundaries blocks explanation and, consequently, classification. From neither perspective are "fuzzy boundaries" part of the explanation of PDs. By contrast our theoretical synthesis accords them an explanatory role and offers a new ontological means of considering them.

These arguments show that if one wants to discuss ontology, the HPC model's theoretical synthesis is better than the operational synthesis. Indeed, in the former, the discovery of something real is the major guide of the research; in the latter it is not, having only the guide of pragmatic aims. In the remaining sections of this work, we will explore the kind of ontology we are dealing with when we approach PDs from within an HPC framework.

\section{Our second proposal: the ontology of HPC compared to PDs}

We have specified how the HPC model could be seen as an 
alternative to essentialism and how it could imply the synthesis between discrete and continuous systems, i.e., if we conceive of the HPC model geometrically, the sets conceived as a circular (closed) line visually evidence the discreetness of clusters (discreetness of PDs), and the intersection of sets visually evidence the continuous element of the clusters (e.g., the comorbidity of PDs, see section 4). Once the HPC model has been adopted, what is the PDs ontology we end up with?

At this point we have to remember (again) that the HPC model was developed in the literature of the philosophy of biology - specifically in relation to the problem of species (Boyd 1991). As already stressed in section 4.2 , it is important to bear in mind that applying this model to PD classification is an extrapolation. We have taken a model from one field (philosophy of biology) and uncritically applied it to another (philosophy of psychiatry). To date, little attention has been paid to this in the literature of the philosophy of psychiatry. However, we think it is central to the present discussion. Apart from the aforementioned consequences of conceiving of PDs as natural kinds (which is considered problematic), the heterogenetic conceptualization of PDs' properties (namely the fact that there is no agreement between scholars regarding what kind of "stuff" the properties of HPC - in the context of PDs - should correspond to) and the ambiguous concept of underlying mechanisms (see section 4), another consequence of this extrapolation concerns ontology. Within the philosophy of biology there is (almost) no ambiguity concerning references to ontology: all scholars agree that - for example - molecules, cells, lions and frogs are objects that exist in the world independently of our minds. Furthermore, in this field of study, there is a general consensus that all biological objects can be reduced (in the end) to physical objects. This kind of ontological reductionism is called token-physicalism (see Kaiser (2011, p. 457) and Kaiser (2015, p. 52). As Rosenberg (2006) wrote "we're all physicalists now" (p. 4). Therefore, in the philosophy of biology, there is a significant agreement within discussions concerning ontology. ${ }^{27}$ However, things change when we focus on other fields, for example, the philosophy of mind. In this context, when scholars refer to (say) ontological reduction, they have to specify the kind of ontological reduction to which they are referring. For example, are they referring to type or property physicalism (Kaiser 2015, p. 52)? Indeed here, the consensus around ontology is more delicate. The debate becomes even more confused if we turn to the philosophy of psychiatry. In literature, the nature of PDs is approached in two main ways: on one hand, the ontological status of PDs is discussed in terms of natural kinds, namely, are PDs genuine natural kinds or not? On the other, the ontological status of PDs is formulated in more specific terms of the validity of the diagnosis. Concerning the former, it seems that there is (as already mentioned in section 4.2), an impasse with regard to treating PDs as natural kinds. Indeed, despite a rich literature (Craver, 2009; Cooper 2012, chapter 4; Hacking 1998, 1999; Haslam 2000; Kendler, Zachar and Craver 2011; Sabbarton-Leary, Bortolotti and Broome 2015; Zachar 2000, 2002, 2014; Zachar and Kendler 2007), there is neither philosophical consensus nor etiological evidence of this. In relation to this point, we concur with the cautious position developed by Cooper (2012). While in previous works (Cooper 2005) she asserts that certain PDs could be viewed as natural kinds, she later retracts her position, asserting that the term natural kind "has become encrusted with metaphysical baggage" (2012, p. 62). For this reason, she proposes a more "weak claim" (p. 63) saying that in order to be classified, PDs only have to be "repeatables": "some entities in the world are alike, and will behave in similar ways" (p. 62). We are sympathetic to this position and will return to it later.

To return to the two approaches: while the first - namely, PDs as natural kinds - seems to arrive at a philosophical impasse ${ }^{28}$ we think the second could be philosophically more fertile. Different concepts of validity have been proposed which attempt to confirm the reality of PDs (Kendler and Parnas 2012; Zachar et al. 2015). We cannot explore such a large quantity of literature here. We simply wish to stress that one reason for this plurality, depends on the fact that validity changes its form, according to the theory of knowledge we undertake. Since there is a plurality of different kinds of theories of knowledge, one consequence is a plurality of the concepts of validity too (e.g., Zachar 2012). For a simplified (and polarized) picture, we focus on the framework elaborated by Aragona (2015) who writes that theory of knowledge tends toward two directions:

(1) one tends toward a correspondence between our representations and external reality. In this case the development of science consists of successive discoveries that increase the approximation of our representations/models/ theories/diagnosis in relation to external reality. Validation in psychiatric nosology relies on "the act of showing that our diagnosis corresponds to something external to the diagnostic concept, such as a laboratory marker or neurobiological features" (Aragona 2015, p. 42);

(2) another tends towards an active construction of our concepts that does not represent the world as it is, but as we see it. The development of science in this case consists of a movement from less to more adequate models. Validation shows that diagnosis is adequate, namely, it is in line with the predictions and needs of the models (ibid.).

In the former case, validation involves the correspondence of diagnosis with the external world. In the latter, validation 
concerns the concept of adequacy (i.e., a model is adequate when it permits scientific goals). In the following section, we wish to compare the concepts of validity, proposed by Aragona, with the object of our discussion. With the aforementioned scenarios in mind, we can reasonably argue that the operational synthesis that we discussed in section 2 could be located in (2), given that we have already identified it with Zachar's notion of practical kinds (section 3). Indeed, the operational synthesis could be seen as a practical procedure to obtain adequate models for clinical success. By contrast, our theoretical synthesis could be located in (1). Indeed, the HPC model assumes that similarities (between diagnostic concepts and patients and between patients and patients) provide certain information with regard to the real features of the world (i.e., features of human beings). Nevertheless, in comparison with Aragona's scenario (1), the limitations of the HPC model are that we cannot validate PDs through "laboratory markers" or "neurobiological features". The lack of etiological evidence is one of the big problems of validation in psychiatry. Even efforts to bypass, re-conceptualize or force the problem (Ghaemi 2012; Jablensky 2012; Sabbarton-Leary, Bortolotti and Broome 2015) ${ }^{29}$ in the practice of psychiatry, leads it to a dead end. ${ }^{30}$ Our proposal tries to avoid this problem through a change in perspective. Indeed, our tactic is to shift the problem to the HPC model because we think that in this framework, ontology could be grasped in a different way. Indeed, concerning validity, the HPC model can be seen as a mirror device of external reality.

The continuous corroboration of cluster/network groups of symptoms suggests that they develop in a non-random manner (Rodrigues and Banzato 2015, p. 51). There is some degree of robustness..$^{31}$ In other words, the HPC model does not give back validation in terms of (say) biological etiology, but it does mirror indirect information in terms of the robustness of the cluster/network group of symptoms (e.g., features of human beings).

The mirror device metaphor is not only proposed as a suggestion. As illustrated in figure 3, it has explanatory power. The "PD" is the psychiatric disorder under attention; the "mirror device" is the HPC model; "us" are the researchers studying that disorder. What is mirrored is the robustness of the cluster of symptoms. Researchers cannot directly "see" the PD, rather they see it in the reflected image of its robustness, namely, they see a certain number of symptoms (and their relations) that do not change (to a certain degree) over time. Concerning the epistemological element, we can affirm that the HPC model, viewed as a mirror device, is an epistemological device (i.e., it is a model) developed to grasp the ontological features of the world (i.e., robustness of clusters/ networks of symptoms). This metaphor is explanatory insofar as it provides a clear idea of how the HPC model can be seen as a mirror device of external reality.

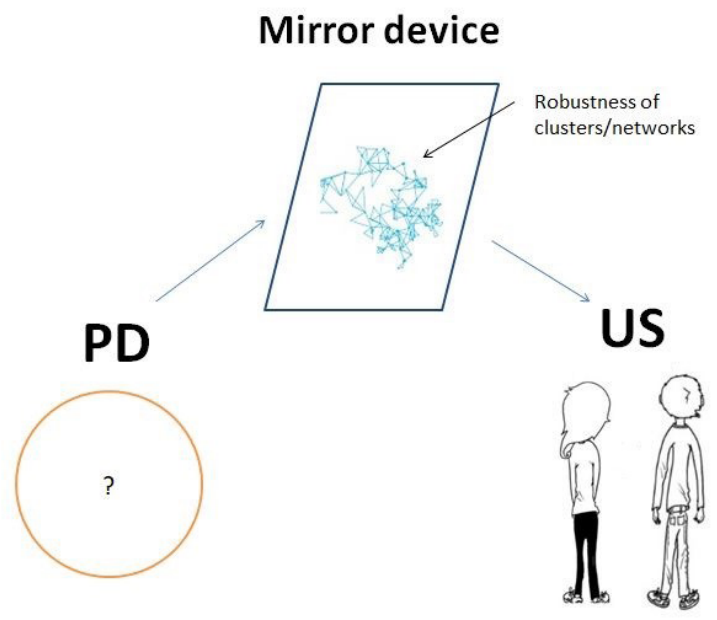

Figure 3. The visualization of the HPC model, conceived as a mirror device of external reality. The "PD" circle represents the disorder being considered; the parallelogram represents the metaphor of the HPC model as a mirror device; the nodes and lines in the mirror represent the robustness of the cluster/network of the PD; the "US" people represent researchers; the arrows represent the reflection of the image. Worthy of note is that this image is a snapshot of reality, namely, it is a moment in time. Instead the term "robustness" is embedded in time, more specifically, certain clusters of properties are robust compared to a PD mean, and at different times, PDs tend to present those properties.

29. Ghaemi proposes reworking the DSM-5 in order to "force" the research to uncover etiological evidence; Jablensky, historically and conceptually, reflects on concepts central for PDS studies, such as "disorders" and "disease", underlying also that "classifications are provisional and pragmatic tools, which carry with them a danger of unwarranted reifications" (Kendler and Parnas 2012, p. 75); Finally, in light of the problem of seeing PDs as natural kinds, Sabbarton-Leary, Bortolotti and Broome (2015) try to "bypass" this, reusing the concept of "para-natural kinds" (introduced for the first time by Sorensen (2011, p. 113)) and refer to PDs as an "absence" of natural kinds.

3o. Of course the Mental Health Research Domain Criteria (RDoC) project works to discover etiological evidence: "the RDoC approach represents a true paradigm shift in the classification of mental disorders, moving away from defining disorders based on descriptive phenomenology, and instead focusing on disruptions in neural circuitry as the fundamental classificatory principle" (First 2012, p. 16), referring to Kendler and First (2010). Despite certain optimism relating to the RDoC (Tabb 2015), no conclusive results have yet been obtained (First 2012, p. 16) referring to Kendler and First (2010). Given that these lines of research have not yet led to relevant results, we will, therefore, not elaborate on them further.

31. In a similar way, Slater (2015) with his idea of the Stable Property Cluster (SPC) model, states how the stability of the clusters (not its causes, e.g., underlying mechanisms) "is apt for induction and explanation" ( $p .396)$. What Slater calls "stability" is similar to what we call "robustness", insofar as both refer to an ontological "tendency" for the properties to cluster together, permitting induction and explanations. 
We believe that, by seeing the HPC as a mirror device to detect the robustness of PDs' patterns, ${ }^{32}$ the way the model works could clarify the ontological status of PDs, in the sense that it provides a means of viewing PDs as robust clusters/ networks of symptoms and symptom relationships. Our suggestion that validity is located within the HPC model itself, does not solve the problem of psychiatric nosology, but it does present a new way of addressing the issue of validation in investigations into PDs.

The position we have just outlined, is in line with Cooper (2012, p. 62-63) who writes about the possibility of focusing the classification of PDs on the straightforward concept of similarities, rather than the "metaphysical[ly] encrusted" concept of natural kind. More specifically, she replaces the notion of natural kind with the notion of "repeatables", which refer to the fact that "some entities in the world are alike, and will behave in similar ways" (p. 62). Concerning PDs, she writes: "if we consider individual cases of mental disorder some can be seen to be similar to each other" (ibid.). She suggests that in this way, we avoid the metaphysical problems to which the former approach (i.e., PDs as natural kind) gives rise. Cooper (2012) also recognizes that her proposal of "repeatables" is a "very weak claim" (p. 63). Nevertheless, our account of the HPC model as a mirror device, reflective of ontology, could also provide the opportunity to instantiate Cooper's concept of similarities. More specifically, we wish to propose that what we "see" in the mirror device could be intended as the repeatables by Cooper (2012). Let us consider in which sense this could be the case. We have already stressed that our version of the HPC model, compared to PDs reflects the real world - specifically in the sense of the robustness of its clusters (or networks). Although these are not always constant, they are certainly not random! Furthermore, we can reasonably say that there are certain clusters (or part of clusters) that are more or less robust in the sense that they are often similar to one other. We can also affirm that, what the mirror device reflects (namely, the robustness of clusters), can be seen as an instantiation of Cooper's repeatables. In this way, we propose to see the robustness of clusters as a specific instantiation of the general concept of similarity by Cooper. In addition, we could claim that the robustness of these clusters/ repeatables refer to the ontology of PDs (namely it refers to and reflects on human beings' features).
Furthermore, Cooper's account of repeatables solves the discrete/continuous debate in line with our efforts (see section 3.1). Indeed, Cooper argues that whether a PD is discrete or continuous does not influence the concept of repeatables which can work even when psychiatrists conduct inductive diagnostic inference (p. 62). In a similar way, we propose viewing discrete and continuous as compatible because they are both implied in a single model (HPC model, see section 4.3) and, for this reason, present no problems with regard to inductive diagnostic inference.

More generally, we concur with Cooper in saying that an effective way of approaching the classification of PDs is by returning to the intuitive concept of similarities. ${ }^{33}$ We agree, because efforts toward discovering an etiological basis to PDs could lead research to a dead end. In this vein, we are also in line with Kendler when, in the context of discussing the impossibility of new, future, essentialist evidences about PDs, ${ }^{34}$ he states there will "no more 'spirochete-like' discoveries" (Kendler 2005, p. 433).

In summary, the operational synthesis could be seen as a method in line with Zachar's practical kinds that assumes the classification of PDs as a pragmatic system to achieve scientific goals. On the other hand, the significance of the proposed theoretical synthesis must be traced back to the ontological dimension of the HPC model. We noted that the ontological implications of applying the HPC model to PDs are a grey area in the literature. We proposed conceiving of the HPC model as a mirror device that gives indirect information - in terms of the robustness of cluster/networks - about the structure of the world (e.g., features of human beings). All of this is in line with the account of repeatables by Cooper (2012). This encourages the direction of our proposal.

\section{Conclusions}

Our proposal was to link the classic debate concerning the boundaries of PDs with the HPC model in order to show how this model could be seen as an alternative answer to the operational synthesis, proposed by practical psychiatrists. More specifically, we called the synthesis that we derived from the

32. In terms of the kind of realism we are dealing with, we could say that we are line with Schaffner (2012) who writes about a "conditioned realism". He claims that the "direct evidence" of something is conditioned by the acceptance of auxiliary assumptions, i.e., one that describes how instruments are used to observe the entity of interest works and another that testifies to the absence of other plausible and incompatible theories for the same "direct evidences". We are conditioned to and accept the assumption, according to which the HPC model, as a theoretical instrument, mirrors reality, giving us - in this context - "indirect evidences" of this reality.

33. In a similar way, in section 4.2, we returned to a "deflated" idea of the HPC model.

34. The "spirochete discovery" refers to the discovery that general paresis was caused by a bacterial microorganism and could be cured with penicillin. This discovery reinforced bacteria theories (i.e., diseases were caused by bacteria) that were, in turn, a-critically applied to PDs (see Deacon (2013); Kendler, Zachar and Craver (2011) and Kendler (2005)). Kendler, with the slogan, "no more 'spirochete-like' discoveries" underlines his skepticism of the future possibility of identifying bacterial infections as causes (essential properties) of PDs. 
HPC model, a theoretical synthesis. In short, what we have proposed is a synthesis between discrete and continuous systems that is ontologically informative. Firstly, we argued how this synthesis could be visualized in the HPC model. Secondly, after adopting the HPC model, we specified the kind of ontology it provides for PDs.

More specifically in relation to this last point, we proposed a new kind of ontology, using the HPC model, which could be seen as a mirror device of external reality. Nonetheless, "external reality" does not mean etiological evidence but rather the robustness of the cluster of symptoms. Indeed, our overall suggestion for this work is that the robustness of clusters of symptoms is an important ontological feature that can help in the identification and classification of PDs.

Finally, this article is focused primarily on ontology. Nevertheless, two final remarks concerning explanations are necessary. In general, we believe the HPC/network of symptoms model is a useful tool for clarifying the classification of PDs. Nevertheless, we do not believe it to be unique. This is because various and complex factors - including personal history, social beliefs, cultural influences, government institutions and historical context - are at play. We suggest approaching explanations with an attitude of pluralism (Cooper 2012, p. 63; Haslam 2002a, p. 204).

For example, if we conceive of the HPC model as a network of symptoms, these could be viewed as a central matrix of symptom-symptom relationships; above and below exist other levels of explanation (biological, psychological, social, cultural), see Kendler (2012). For example, the cause of a mental disorder could be a traumatic event in a patient's life, and this fundamental factor must be part of the general knowledge relating to this disorder, even if it is not part of the HPC model. ${ }^{35}$ In this vein, the HPC model must form part of more inclusive studies. A further final remark is necessary. Our argument in relation to the classification of PDs' boundaries is philosophical and theoretical. Diagnosis and treatment belong to different disciplines and research domains. Between them exist discrete boundaries which must be respected. However, we believe that cross-cutting and integrative approaches will prove fruitful, if they are elaborated critically and scientifically, and could reveal exciting new research directions, ripe for examination.

\section{ACKNOWLEDGEMENTS}

I would like to thank Francesca Merlin, Katherine Waters, Isabelle Drouet, and two very helpful anonymous referees.

\section{BIBLIOGRAPHY}

ADRIAENS, Pieter R., DE BLOCK Andreas. 2013. Why We Essentialize Mental Disorders. Journal of Medicine and Philosophy, 38, 107-127. Lien

APA, (1980). Diagnostic and Statistical Manual of Mental Disorders (3rd ed.), American Psychiatric Press: Washington, DC.

APA, (1994). Diagnostic and Statistical Manual of Mental Disorders, (4th ed.), American Psychiatric Press: Washington, DC.

ARAGONA, Massimiliano. 2015. Rethinking Received Views on the History of Psychiatric Nosology: Minor Shifts, Major Continuities. In ZACHAR, Peter (ed.), STOYANOV Drozdstoy (ed.), ARAGONA Massimiliano (ed.), JABLENSKY Assen (ed.). Alternative Perspectives on Psychiatric Validation DSM, ICD, RDoC, and Beyond. Oxford, UK: Oxford University Press, 27-46. Lien

BJELLAND, Ingvar, LIE Stein A., DAHL Alv A., MYKLETUN Arnstein, STORDAL Eystein, KRAEMER Helena C. 2009. A Dimensional Versus a Categorical Approach to Diagnosis: Anxiety and Depression in the HUNT 2 Study. International Journal of Methods in Psychiatric Research, 18(2), 128-137, $\underline{\text { Lien }}$

BORSBOOM, Denny. 2008. Psychometric Perspectives on Diagnostic Systems. Journal of Clinical Psychology, 64, 1089-1108 Lien

Id. 2017. A network theory of mental disorders. World psychiatry, 16(1), 5-13. Lien

BORSBOOM, Denny, CRAMER Angelique O. 2013. Network Analysis: An Integrative Approach to the Structure of Psychopathogenesy. The Annual Review of Clinical Psychology, 9, 91-121 Lien

BORSBOOM, Denny, CRAMER Angelique O., KALIS Annemarie. 2019. Brain Disorders? Not Really: Why Network Structures Block Reductionism in Psychopatology Research. Behavioral and Brain Sciences, 42, e2, 1-63. Lien

BOYD, Richard. 1988. How to be a moral realist. Contemporary Materialism, 307 - 356. Lien

Id. 1991. Realism, Anti-Foundationalism and the Enthusiasm for Natural Kinds. Philosophical Stud- 

LOGY OF PSYChiatric Disorders (PDs) USing the Homeostatic Property Cluster (HPC) MODel

ies, 61, 127-148. Lien

Id. 1999. Homeostasis, Species, and Higher Taxa. In WILSON, Robert A. (ed.). Species: New Interdisciplinary Essays, Cambridge, MIT Press. Lien

BOLTON, Derek. 2008. What Is Mental Disorder? An Essay in Philosophy, Science, and Values. Oxford: Oxford University Press. Lien

Id. 2012. Classification and Causal Mechanisms: a Deflationary Approach to the Classification Problem. In KENDLER, Kenneth (ed.), PARNAS Josef (ed.). Philosophical Issues in Psychiatry II: Nosology. Oxford, UK: Oxford University Press, 6-11. Lien

BROMAN-FULKS, Joshua, DEACON Brett, OLATUNJIC Bunmi, BONDY Carmen, ABRAMOWITZ Jonathan, TOLIN David. 2010. Categorical or Dimensional: A Reanalysis of the Anxiety Sensitivity Construct. Behavior Therapy, 41, 154-171. Lien

CAHALAN, Susannah. 2019. The Great Pretender: The Undercover Mission That Changed Our Understanding of Madness. Grand Central Pub. Lien

CRAVER, Carl F. 2007. Explaining the Brain. Clarendon Press: Oxford. Lien

Id. 2009. Mechanisms and Natural Kinds. Philosophical Psychology, 22, 575-594. Lien

COOPER, Rachel. 2005. Classifying Madness: A Philosophical Examination of the Diagnostic and Statistical Manual of Mental Disorders. Dordrecht, Springer. Lien

Id. 2007. Psychiatry and Philosophy of Science. Stocksfield, UK, Acumen.

Id. 2012. Is Psychiatric Classification a Good Thing? In KENDLER, Kenneth (ed.), PARNAS Josef (ed.). Philosophical Issues in Psychiatry II: Nosology. Oxford, UK: Oxford University Press, 61-69. Lien

DEACON, Brett. 2013. The Biomedical Model of Mental Disorder: A Critical Analysis of its Validity, Utility, and Effects on Psychotherapy Research. Clinical Psychology Review. Lien

DECKER, Hannah S. 2007. How Kraepelinian was Kraepelin? How Kraepelinian are the neo-Kraepelinians? - from Emil Kraepelin to DSM-III. History of Psychiatry. 18(3), 337360. Lien
DEWEY, John. 1925. Experience and Nature, Dover, New York, NY.

ERESHEFSKY, Marc. Fall 2017 Edition. Species, The Stanford Encyclopedia of Philosophy, ZALTA, Edward N. (ed.), Lien

ERESHEFSKY, Marc, REYDON Tomas. 2015. Scientific kinds: a Critique of HPC Theory and a Proposal for an Alternative Account. Philosophical Studies, 172, 969-986. Lien

FINE, Arthur. 1984. The Natural Ontological Attitude. In Scientific Realism. University of California Press, Berkeley, CA, 83-107. Lien

FIRST, Michael B. (2012). The National Institute of Mental Health Research Domain Criteria (RDoC) Project: moving Towards a Neuroscience-Based Diagnostic Classification in Psychiatry. In KENDLER, Kenneth (ed.), PARNAS Josef (ed.). Philosophical Issues in Psychiatry II: Nosology. Oxford, UK: Oxford University Press, 12-18. Lien

FRANCES, Allen, MACK Avram, FIRST Michael, WIDIGER Thomas, ROSS Ruth, FORMAN Leslie, DAVIS Wendy W. 1993. DSM - IV Meets Philosophy. The Journal of Medicine and Philosophy, 19, 207-218. Lien

FRIED, Eiko I. 2015. Problematic Assumptions Have Slowed Down Depression Research: why Symptoms, not Syndromes are the Way Forward. Frontiers in Psychology, 6, 1-11, DOI: 10.3389/fpsyg.2015.00309. Lien

GLASOFER, Deborah R., BROWN Amanda J., RIEGEL Melissa. 2015. Structured Clinical Interview for DSM-IV (SCID). Encyclopedia of Feeding and Eating Disorders. Lien

GHAEMI, Nassir S. 2012. Taking Disease Seriously: Beyond "Pragmatic" Nosology. In KENDLER, Kenneth (ed.), PARNAS Josef (ed.). Philosophical Issues in Psychiatry II: Nosology. Oxford, UK: Oxford University Press, 41-53. Lien

GROB, Gerald N. 1991. Origins of DSM-I: a study in appearance and reality. American Journal of Psychiatry, 148, 42131. Lien

HACKING, Ian. 1998. Mad Travelers: Reflections on the Reality of Transient Mental Illnesses. University of Virginia Press. Lien

Id. 1999. The Social Construction of What? Harvard University Press. Lien

HASLAM, Nick. 2000. Psychiatric Categories as Natural 

LOGY OF PSYChiatric Disorders (PDs) USing the Homeostatic Property Cluster (HPC) MODel

Kinds: Essentialist Thinking About Mental Disorder. Social Research, 67, 1031-1058. Lien

Id. 2002a. Kinds of Kinds: A Conceptual Taxonomy of Psychiatric Categories. Philosophy, Psychiatry, Psychology, volume (3), 203 - 217. Lien

Id. 2002b. Practical, Functional, and Natural Kinds. Philosophy, Psychiatry, Psychology, volume (9), No. 3, $238-241$. Lien

Id. 2003. Categorical versus dimensional models of mental disorder: The taxometric evidence. Australian \& New Zealand Journal of Psychiatry, 37(6), 696704. Lien

HAUSWALD, Rico, KEUCK Lara. 2017. Indeterminacy in Medical Classification: On Continuity, uncertainty, and Vagueness. In KEIL, Geert (ed.), KEUCK Lara (ed.), HAUSWALD Rico (ed.). Vagueness in Psychiatry, 93-116. Lien

JABLENSKY, Assen. 2012. The Nosological Entity in Psychiatry: a Historical Illusion or a Moving Target? In KENDLER, Kenneth (ed.), PARNAS Josef (ed.). Philosophical Issues in Psychiatry II: Nosology. Oxford, UK: Oxford University Press, 77-94. Lien

Id. 2016. Psychiatric Classifications: Validity and Utility. World Psychiatry, 15, 26-31. Lien

JAMES, William. 1907. Pragmatism and the Meaning of Truth. Harvard University Press, Cambridge, MA. Lien

KAISER, Marie. 2011. The Limits of Reductionism in the Life Sciences. History and Philosophy of the Life Sciences. Volume (33), No. 4, Causation and Disease, 453-476. Lien

Id. 2015. Reductive Explanation in the Biological Sciences. History, Philosophy and Theory of the Life Sciences, Springer. Lien

KASNIN, Jacob S. 1994. The acute schizoaffective psychoses. Am J Psychiatry, 151(6 Suppl), 144-54, Lien

KENDELL, Robert, JABLENSKY Assen. 2003. Distinguishing between the Validity and Utility of Psychiatric Diagnoses. American Journal of Psychiatry, 160, 4-12. Lien

KENDLER, Kenneth, ZACHAR Peter, CRAVER Carl. 2011. What Kinds of Things Are Psychiatric Disorders? Psychological Medicine, 41, 1143-1150. Lien
KENDLER, Kenneth, PARNAS Josef. 2012. Philosophical Issues in Psychiatry II: Nosology. Oxford, UK: Oxford University Press. Lien

KENDLER, Kenneth, FIRST Michael. 2010. Alternative futures for the DSM revision process: iteration v. paradigm shift. British Journal of Psychiatry, 197 (4), 263 - 5. Lien

KENDLER, Kenneth. 2005. Toward a Philosophical Structure for Psychiatry. American Journal of Psychiatry, 162, 433-440. Lien

Id. 2012. Levels of explanation in psychiatric and substance use disorders: implications for the development of an etiologically based nosology. Molecular Psychiatry, 17, 11-21. Lien

KESHAVAN, Matcheri, MORRIS David, SWEENEY John, PEARLSON Godfrey, THAKER Gunvant, SEIDMAIN Larry, EACK Shaun, TAMMINGA Carol. 2011. A dimensional approach to the psychosis spectrum between bipolar disorder and schizophrenia: The Schizo-Bipolar Scale, Schizophrenia Research, 133(1-3), 250-254. Lien

KHALIDI, Muhammad Ali. 1993. Carving Nature at The Joints. Philosophy of Science, volume (60), No. 1, 100- 113. Lien

KRAEPELIN, Emil. 1913. Lectures on Clinical Psychiatry. JOHNSTONE, Thomas (ed.), 3rd English ed. (New York: William Wood \& Co.; reprinted, Bristol: Thoemmes Press, 2002); originally published in 1905 as Einführung in die Psychiatrische Klinik. Zweiunddreißig Vorlesungen, 2nd ed.

MUTHéN, Bengt. 2006. Should Substance use Disorders be Considered as Categorical or Dimensional? American Psychiatric Association, Journal compilation, Society for the Study of Addiction, 101, (Suppl. 1), 6-16. Lien

MURPHY, Dominic. 2006. Psychiatric in the Scientific Image, Cambridge: MIT Press. Lien

Id. 2015. Validity, Realism and Normativity. In ZACHAR, Peter (ed.), STOYANOV Drozdstoj (ed.), ARAGONA Massimiliano (ed.), JABLENSKY Assen (ed.), Alternative Perspectives on Psychiatric Validation DSM, ICD, RDoC, and Beyond, Oxford, UK: Oxford University Press, 60-75. Lien

RODRIGUES, Adriano, BANZATO Claudio. 2015. Reality and Utility Unbound: An Argument for Dual-Track Nosologic Validation. In ZACHAR, Peter (ed.), STOYANOV Drozdstoj (ed.), ARAGONA Massimiliano (ed.), JABLENSKY As- 
sen (ed.), Alternative Perspectives on Psychiatric Validation DSM, ICD, RDoC, and Beyond, Oxford, UK: Oxford University Press, 47-59. Lien

ROSENBERG, Alex. 2006. Darwinian reductionism. Or, how to stop worrying and love molecular biology. Cambridge, University of Chicago Press. Lien

ROSENHAN, David. 1973. On Being Sane in Insane Places. Science, 179, 379-399. Lien

RUSCIO, John, HASLAM Nick, RUSCIO Ayelet. 2006. Introduction to the Taxometric method: a Practical Guide. Mahwah, NJ: Erlbaum. Lien

SABBARTON-LEARY, Nigel, BORTOLOTTI Lisa, BROOME Matthew. 2015. Natural and Pare-Natural Kinds in Psychiatry. In ZACHAR, Peter (ed.), STOYANOV Drozdstoj (ed.), ARAGONA Massimiliano (ed.), JABLENSKY Assen (ed.), Alternative Perspectives on Psychiatric Validation DSM, ICD, RDoC, and Beyond, Oxford, UK: Oxford University Press, 7693. Lien

SCHAFFNER, Kenneth. 2012. A Philosophical overview of the Problems of Validity for Psychiatric Disorders. In KENDLER, Kenneth (ed.), PARNAS Josef (ed.). Philosophical Issues in Psychiatry II: Nosology. Oxford, UK: Oxford University Press, 170-189. Lien

SHEAR, Katherine, BJELLAND Ingvar, BEESDO Katja, GLOSTER Andrew, EITTCHEN Hans-Ulrich. 2007. Supplementary Dimensional Assessment in Anxiety Disorders. International Journal of Methods in Psychiatric Research, 16(S1), S52-S64, Lien

SORENSEN, Roy. 2011. Para-natural Kinds. In CAMPBELL, Joe (ed.), O'ROURKE Michael (ed.), SLATER Matthew (ed.). Carving Nature at Its Joints: Natural Kinds in Metaphysics and Science. Cambridge, MA: MIT Press. Lien

SZASZ, Thomas. 1960. The Myth of Mental Illness. American Psychologist, 15, 113-118. Lien

TABB, Kathryn. 2015. Psychiatric Progress and the Assumption of Diagnostic Discrimination. Philosophy of Science, 82, 1047-1058. Lien

Id. 2019. Philosophy of Psychiatry After Diagnostic Kinds. Synthese, 196.6, 2177-2195. Lien

TSOU, Jonathan. 2011. The Importance of History for Philosophy of Psychiatry: The Case of the DSM and Psychiatric Classification. Journal of the Philosophy of History, 5, 445-
469. Lien

Id. 2006. Natural Kinds, Psychiatric Classification and the History of the DSM. History of Psychiatry. volume27(4), 406-424. Lien

VAN LOO, Hanna, ROMEIJN Jan-Willem, DE JONGE Peter, SCHOEVERS Robert. 2012. Psychiatric Comorbidity and Causal Disease Models. Preventive Medicine, 57, 748-752. $\underline{\text { Lien }}$

WADE, Derick, HALLIGAN Peter. 2004. Do Biomedical Models of Illness make for good Healthcare Systems? Education and debate, 329, 1398-1401. Lien

WALTERS, Glenn, McGRATH Robert, KNIGHT Raymond. 2010. Taxometrics Polytomous Constructs, and the Comparison Curve Fit Index: A Monte Carlo analysis. Psychological Assessment, 22, 149-156. Lien

WHITAKER, Robert. 2001. Mad in America: Bad Science, Bad Medicine, and the Enduring Mistreatment of the Mentally Ill, New York: Basic Books. Lien

Id. 2010. Anatomy of an epidemic: Magic bullets, psychiatric drugs, and the astonishing rise of mental illness in America, New York: Crown. Lien

WIDIGER, Thomas, SAMUEL Douglas. 2005. Diagnostic Categories or Dimensions? A Question for the Diagnostic and Statistical Manual of Mental Disorders-Fifth Edition. Journal of Abnormal Psychology Copyright, the American Psychological Association, volume (114), No. 4, 494-504. Lien

WILSON, Robert, BARKER Matthew, BRIGANDT Ingo. 2007. When Traditional Essentialism Fails: Biological Natural Kinds, Philosophical Topics, 35, 189-215, Lien

ZACHAR, Peter. 2000. Psychiatric Disorders Are Not Natural Kinds. Philosophy, Psychiatry, Psychology, 7, 167-182. Lien

Id. 2002. The Practical Kinds Model as a Pragmatist Theory of Classification. Philosophy, Psychiatry, \& Psychology, Volume (9), No. 3, 219-227. Lien

Id. 2012. Progress and the calibration of scientific constructs: the role of comparative validity. In KENDLER, Kenneth (ed.), PARNAS Josef (ed.). Philosophical Issues in Psychiatry II: Nosology. Oxford, UK: Oxford University Press, 21-34. Lien

Id. 2014. Metaphysics of Psychopathology. The MIT Press, Cambridge, Massachusetts, London, England. 


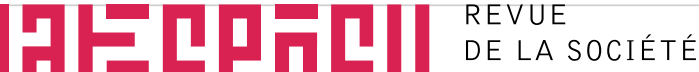 \\ 四的的 \\ DES SCIENCES}

EXPLORING THE BOUNDARIES AND ONTOlogy of Psychiatric Disorders (PDs) Using the Homeostatic Property Cluster (HPC) MODel $\underline{\text { Lien }}$

ZACHAR, Peter, KENDLER Kenneth. 2007. Psychiatric Disorders: A Conceptual Taxonomy. Am J Psychiatry, 164, 557565. Lien

ZACHAR, Peter, STOYANOV Drozdstoj, ARAGONA Massimiliano, JABLENSKY Assen. (2015). Alternative Perspectives on Psychiatric Validation DSM, ICD, RDoC, and Beyond, Oxford, UK: Oxford University Press. Lien

\section{HISTORIQUE}

Article soumis le 20 octobre 2018.

Version révisée soumise le 30 janvier 2020.

Article accepté le 8 octobre 2021.

\section{SITE WEB DE LA REVUE}

https://ojs.uclouvain.be/index.php/latosensu

ISSN 2295-8029

DOI http://dx.doi.org/10.20416/LSRSPS.V8I2.3

SOCIÉTÉ DE PHILOSOPHIE DES SCIENCES (SPS)

École normale supérieure

45 , rue d'Ulm

75005 Paris

www.sps-philoscience.org
CONTACT ET COORDONNÉES :

Marco Casali

Department of Philosophy, Sapienza, University of Rome, Italy and Institut d'histoire et de philosophie des sciences et des techniques (IHPST), CNRS \& University of Paris 1 Panthéon-Sorbonne, France marcomarcellocasali@gmail.com

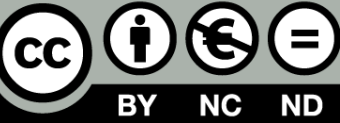

